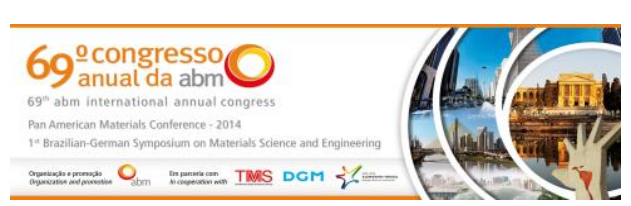

Tema: Produtos metálicos não-ferrosos

\title{
INFLUÊNCIA DA ADIÇÃO DE ARGÔNIO SOBRE A REDUÇÃO A PLASMA DA HEMATITA*
}

Anna Paula Littig Berger ${ }^{1}$

Adonias Ribeiro Franco Júnior ${ }^{2}$

\section{Resumo}

O objetivo do presente trabalho foi estudar a influência da adição de argônio à atmosfera de redução a plasma sobre a redução de pós de hematita. Os experimentos de redução foram realizados em reator a plasma pulsado DC, sob pressão de $533 \mathrm{~Pa}$, temperatura de $380^{\circ} \mathrm{C}$, tempo de $60 \mathrm{~min}$, fluxo total de hidrogênio e de argônio de $400 \mathrm{~cm}^{3} / \mathrm{min}$ e variando os teores de argônio e hidrogênio. Os resultados mostram que os aglomerados de partículas após redução possuem um aspecto esponjoso. Verificou-se que o uso de uma mistura gasosa contendo $2 \%$ de $\mathrm{Ar}$ e $98 \%$ de $\mathrm{H}_{2}$ permite um aumento de aproximadamente $7,76 \%$ na fração de redução.

Palavras-chave: Redução; Plasma; Argônio; Hematita.

\section{INFLUENCE OF ARGON ON PLASMA REDUCTION OF HAEMATITE POWDERS}

\begin{abstract}
The aim of this work was to study the influence of argon on the plasma reduction of haematite powders. The reduction experiments were carried out in a DC pulsed plasma reactor, at $380^{\circ} \mathrm{C}$, for 60 minutes, under gas flow rates of $400 \mathrm{~cm} 3 / \mathrm{min}$ at $533 \mathrm{~Pa}$, using different amounts of argon and hydrogen in the reduction atmosphere. The results show that the powder particles exhibited a spongy aspect after the reduction experiments. Adding $2 \%$ of argon and $98 \%$ of hydrogen in the reduction atmosphere led to an increase of about $7.76 \%$ in the reduction fraction.
\end{abstract}

Keywords: Reduction; Plasma; Argon; Haematite.

1 Graduanda em Engenharia Metalúrgica, Instituto Federal do Espírito Santo, Campus Vitória, Vitória, ES, Brasil.

2 Professor Doutor, Programa de Pós Graduação em Engenharia Metalúrgica e de Materiais (Propemm), Instituto Federal do Espírito Santo, Campus Vitória, Vitória, ES, Brasil.

\footnotetext{
* Contribuição técnica ao 69ำ Congresso Anual da ABM - Internacional e ao 14ํㅡㄹ ENEMET - Encontro Nacional de Estudantes de Engenharia Metalúrgica, de Materiais e de Minas, 21 a 25 de julho de 2014, São Paulo, SP, Brasil.
} 


\section{INTRODUÇÃO}

Nos últimos anos, novas rotas de obtenção de metais vêm sendo pesquisadas e desenvolvidas em decorrência das legislações ambientais cada vez mais rígidas e da crescente preocupação em minimizar as emissões de gases de efeito estufa e de resíduos sólidos.

Chen e colaboradores [1] e Norgate e colaboradores [2] afirmam que os processos de redução carbotérmica a vácuo, redução eletroquímica direta de óxidos refratários (processo CFF Cambridge), redução metalotérmica, moagem de alta energia (mechanical alloying) e redução direta de óxidos usando como agente redutor o hidrogênio são alguns exemplos de novos métodos menos agressivos ao meio ambiente.

A redução de óxidos, na qual o agente redutor é o hidrogênio gasoso, se constitui em uma alternativa bem atraente, já que não há a geração de gases de efeito estufa, tendo como subproduto resultante o vapor d'água. Já no início da década de 1970, Turkdogan e Vinters [3] afirmam que dada a alta cinética do processo de redução em baixas temperaturas, o hidrogênio num futuro próximo poderia ser utilizado na produção em larga escala de ferro esponja. No entanto, para Peña [4] até os dias de hoje o alto custo de produção do hidrogênio, obtido pela reforma de hidrocarbonetos ou pela eletrólise da água, inviabiliza o desenvolvimento industrial de processos baseados no seu uso.

$\mathrm{Na}$ literatura existem alguns trabalhos mostrando que o plasma frio de hidrogênio, em baixas temperaturas, é um poderoso agente redutor dos óxidos de ferro e de cobre. Zhang e colaboradores [5] verificaram que na temperatura de $200^{\circ} \mathrm{C}$, após 60 minutos, é possível a obtenção de cerca de 100\% de cobre metálico a partir do $\mathrm{CuO}$, ao passo que nas mesmas condições, a redução do $\mathrm{CuO}$ não ocorre se utilizado como agente redutor o gás de hidrogênio. Mais recentemente, Rajput e colaboradores [6] mostraram que em temperaturas tão baixas como $300^{\circ} \mathrm{C}$ é possível a obtenção do ferro metálico quando se utiliza como agente redutor o plasma frio de hidrogênio. Os experimentos de Rajput e colaboradores [6] indicam que a redução a gás é cineticamente comparável à redução a plasma somente a partir de temperaturas acima de $800^{\circ} \mathrm{C}$.

Portanto, os resultados reportados na literatura indicam que métodos desenvolvidos com base no uso do plasma frio como agente redutor poderão num futuro próximo se constituir em alternativa que apresenta grandes vantagens, em razão da baixa temperatura de processo, geração e emissão praticamente inexistente de resíduos sólidos e de gases do efeito estufa e possibilidade, no caso de óxidos de ferro, do uso direto de finos de minério evitando tratamentos prévios requeridos tais como sinterização e pelotização.

Não se têm ainda na literatura estudos que mostram a influência do argônio na redução a plasma. Dessa forma, o objetivo do presente artigo foi estudar o efeito da adição do argônio sobre a redução assistida por plasma do pó de hematita. Para isso, foram realizados experimentos de redução, em temperatura e tempo fixos, variando-se o teor de argônio (0,2, 5, 10\%); foram obtidos experimentalmente os graus de redução para cada teor de argônio com base em análises gravimétricas; os produtos de redução após os diferentes experimentos foram analisados através de difração de raios $X$ e avaliou-se a morfologia dos pós de óxido de ferro reduzidos sob os diferentes teores de argônio.

Segundo Inan e Golkowski [7], o plasma é comumente definido como quarto estado da matéria. O plasma é um gás parcialmente ionizado contendo íons, elétrons,

\footnotetext{
* Contribuição técnica ao $69^{\circ}$ Congresso Anual da ABM - Internacional e ao 14ํㅡㄹ ENEMET - Encontro Nacional de Estudantes de Engenharia Metalúrgica, de Materiais e de Minas, 21 a 25 de julho de 2014, São Paulo, SP, Brasil.
} 


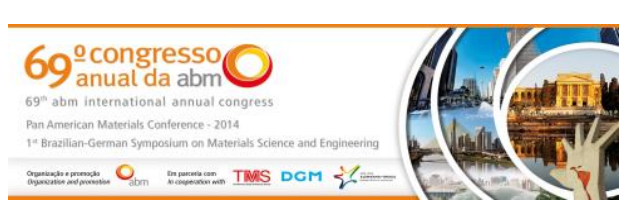

partículas neutras, entre outras espécies. No entanto, nem todo gás ionizado é um plasma e, para ser caracterizado por plasma, o gás precisa ter um grau mínimo de ionização em que todas as partículas carregadas tenham um comportamento coletivo devido às interações coulombianas de longo alcance. Ou seja, a movimentação de uma partícula influencia eletricamente pelo menos duas outras partículas carregadas, de modo que uma movimentação de cargas no interior do plasma faz surgir um campo elétrico para o reestabelecimento do equilíbrio.

De acordo com Flamm [8], o plasma pode ser classificado como: plasma frio ou plasma térmico. O plasma frio, também denominado plasma de não equilíbrio, é caracterizado por apresentar um baixo grau de ionização (1,5 a 2,0\% do volume do gás) e baixa pressão parcial gasosa (entre 100 a $1.000 \mathrm{~Pa}$.). A temperatura molecular do gás é inferior a $1.000^{\circ} \mathrm{C}$, sendo, portanto, menor do que a temperatura dos elétrons livres, que é de aproximadamente $10.000^{\circ} \mathrm{C}$. O plasma térmico ou plasma de equilíbrio, caracterizado por apresentar altas pressões gasosas, possui um grau de ionização maior e praticamente todo o gás se encontra ionizado.

Com o aumento da temperatura, as partículas do gás que se movem adquirem cada vez mais energia e, em consequência, ocorre um aumento da frequência de colisões entre os átomos. No plasma podem ocorrer os seguintes eventos: ionização, dissociação, excitação, relaxação ou emissão e recombinação, representados na figura 1.

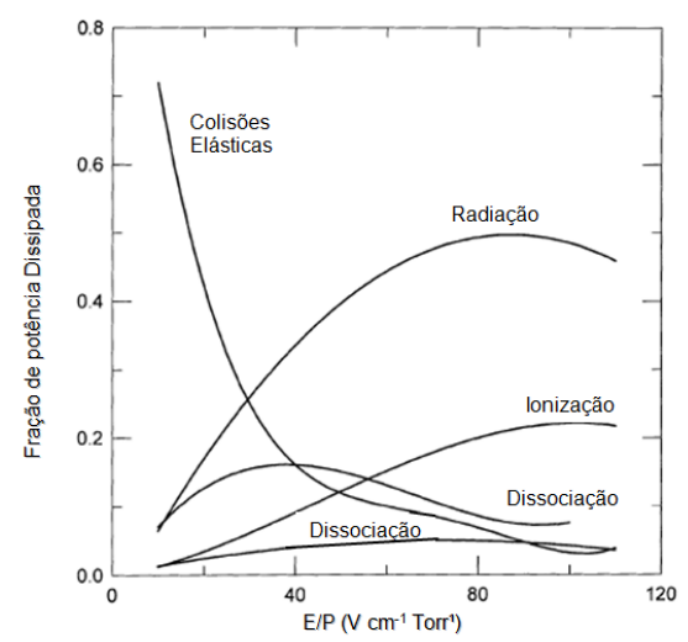

Figura 1. Diferentes eventos produzidos no plasma.

Fonte: Adaptado de Bullard e Lynch [9].

Segundo Bogaerts [10], as descargas luminescentes de corrente contínua podem ser obtidas através da aplicação de uma diferença de potencial entre dois eletrodos situados em um meio gasoso a baixa pressão. Depois da evacuação da câmara, o gás é introduzido e serve como o meio a partir do qual a descarga é iniciada e sustentada. A pressão da câmara é usualmente estabelecida na faixa de 0,1 a 5 torr. A energia do campo eletromagnético aplicado se transfere quase por completo ao gás sob a forma de energia cinética dos elétrons livres. Estes elétrons adquirem energia rapidamente e a perdem mediante uma sequência de colisões. Em pouco tempo, os elétrons adquirem suficiente energia para serem capazes de ionizar ou dissociar as moléculas do gás e aí produzir elétrons secundários por reações de impacto de elétrons. Desta forma, inicia-se o processo de avalanches e descargas.

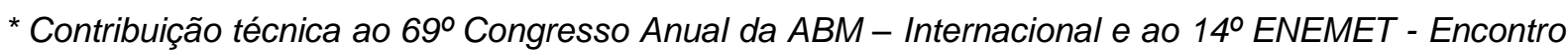
Nacional de Estudantes de Engenharia Metalúrgica, de Materiais e de Minas, 21 a 25 de julho de 2014, São Paulo, SP, Brasil.
} 




Devido à diferença de potencial, os elétrons são acelerados do catodo (-) pelo campo elétrico em direção ao anodo (+) e, durante o percurso, colidem com as moléculas/átomos do gás. As colisões inelásticas levam à excitação, quebra de ligações das moléculas e ionização do gás. As colisões que geram excitações das moléculas são seguidas pela relaxação das moléculas/átomos com emissão de radiação, responsável pelo brilho da descarga (glow discharge). As colisões que produzem ionização liberam mais elétrons e geram novos íons. Por ser de alta energia, a colisão dos íons contra o catodo não só eleva a sua temperatura, como também ejeta átomos, íons e elétrons secundários (pulverização catódica sputtering). Os elétrons gerados, por sua vez, são acelerados pelo campo elétrico para o anodo dando origem a novas colisões-ionização criando-se novos íons e elétrons. Diz-se assim que a descarga luminescente é alto-sustentável.

Para Alves Jr. [11], esse processo continua até a descarga auto sustentar-se, ou seja, não é necessária uma fonte externa para fornecer energia adicional. Este regime é conhecido como descarga anômala ou anormal, a qual é amplamente usada principalmente em tratamentos superficiais, como por exemplo, na nitretação a plasma de metais e ligas. Para valores superiores ao valor máximo da descarga anômala, o aquecimento do catodo será substancial e a emissão termoiônica contribuirá sensivelmente para o aumento da corrente, fazendo com que a descarga seja mantida a uma baixa tensão e alta corrente, originando o arco elétrico.

De acordo com Bogaerts et al. [10], a utilização de fontes de corrente contínua com tensão pulsada visa controlar a potência fornecida ao sistema através da interrupção periódica da tensão. Basicamente essas fontes são conversores de corrente alternada em contínua, acrescidas em sua saída de uma retificação em forma de pulso. Desse modo, a potência fornecida ao sistema é controlada pelo tempo de pulso ligado da fonte (ton). Para o tempo de pulso desligado (toff) a fonte trabalha como se estivesse desligada. A figura 2 ilustra de modo esquemático 0 funcionamento de uma fonte de tensão pulsada.



Figura 2. Representação esquemática do funcionamento de uma fonte de potência de tensão pulsada [10].

Ainda de acordo com Bogaerts e colaboradores [10], os sistemas de descarga luminescente que operam com corrente contínua com tensão pulsada apresentam ainda maior eficiência energética porque a descarga pulsada pode operar em muito maiores picos de corrente e tensão com a mesma potencia média de alimentação. Com isso, melhores taxas de sputtering, ionização e excitação podem ser esperadas. No presente trabalho, esse tipo de sistema de descarga luminescente


Nacional de Estudantes de Engenharia Metalúrgica, de Materiais e de Minas, 21 a 25 de julho de 2014, São Paulo, SP, Brasil.
} 


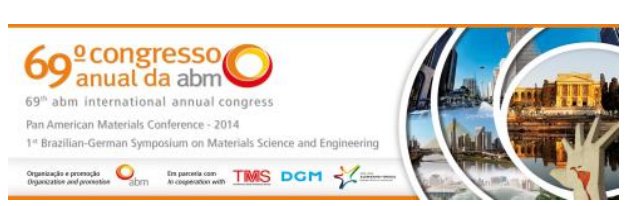

com fonte pulsada foi utilizado nos experimentos de redução a plasma dos óxidos de ferro.

Alves Jr. [11] afirma que a região luminosa próxima ao catodo é chamada de luminescência catódica. A cor da luminescência é característica da composição da mistura gasosa do plasma. Esta região surge devido à excitação dos átomos superficiais bombardeados pelas espécies do plasma. Entre o início dessa luminescência e o catodo existe um espaço escuro denominado bainha catódica que é uma região de baixa concentração de cargas devido ao gradiente de potencial. Após esse espaço escuro existe uma região de alta luminosidade, denominada luminescência negativa. A luminescência negativa juntamente com a região catódica (catodo e bainha catódica) é responsável pela quase totalidade da queda de tensão aplicada entre os eletrodos. É na região de luminescência negativa onde ocorrem os fenômenos de ionização, dissociação, excitação, relaxação ou emissão e recombinação já citados anteriormente.

De acordo com Dembovsky [12], o plasma de hidrogênio possui uma combinação de propriedades termodinâmicas (interações com íons e partículas energéticas) e químicas (interação das espécies do plasma com a partícula do óxido) que o torna grande promissor para o uso na metalurgia extrativa. As partículas ativas do plasma de hidrogênio são capazes de reduzir, em altas taxas, a maioria dos óxidos metálicos. Estudos mostram que o grau de redução depende da quantidade inicial de material, temperatura, tamanho de partículas e do nível de evaporação dos gases presentes, os quais são removidos continuamente através de bombeamento.

O hidrogênio em condições normais de temperatura e pressão existe apenas sob a forma molecular $\mathrm{H}_{2}$. A descarga luminescente do hidrogênio faz surgir espécies tais como $\circ \mathrm{H}$ atômico e o cátion $\mathrm{H}^{+}$cujos efeitos como agentes redutores podem ser vistos no Diagrama de Ellingham Richardson (figura 3).

As espécies $\mathrm{H}$ e $\mathrm{H}^{+}$são capazes de reduzir praticamente todos os sistemas de óxidos apresentados no diagrama.

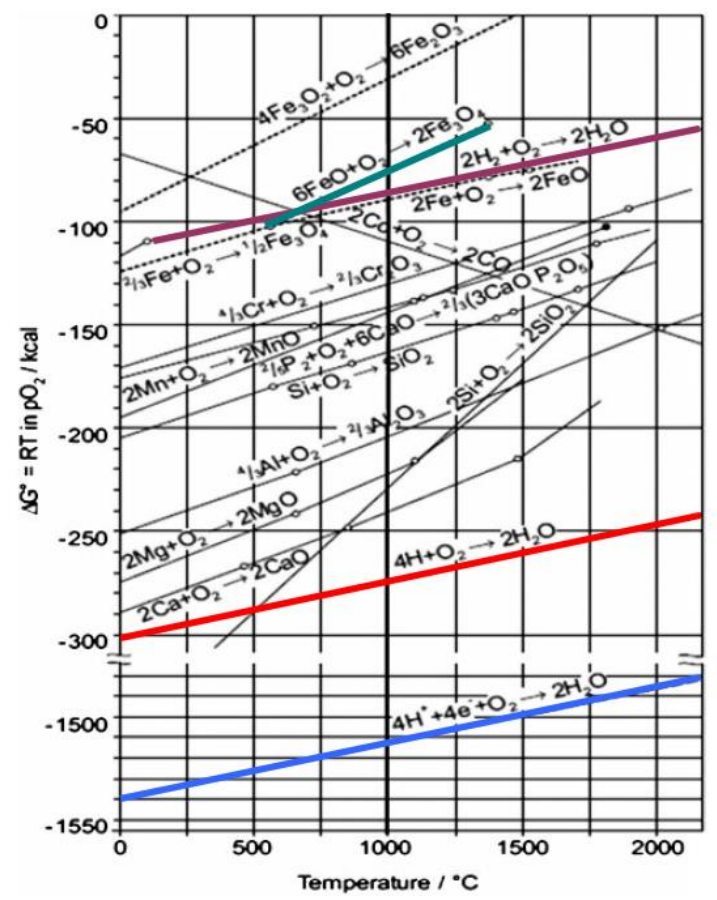

Figura 3. Diagrama de Elligham [6].

* Contribuição técnica ao 69 Congresso Anual da ABM - Internacional e ao 14ํㅡㄹ ENET - Encontro Nacional de Estudantes de Engenharia Metalúrgica, de Materiais e de Minas, 21 a 25 de julho de 2014, São Paulo, SP, Brasil. 


\section{MATERIAIS E MÉTODOS}

\subsection{Material de Partida}

Os pós de hematita de alta pureza, adquiridos da Sigma Aldrich e que foram usados no presente trabalho para os experimentos de redução a plasma, possuem teor de $99,0 \%$ de $\mathrm{Fe}_{2} \mathrm{O}_{3}$ e granulometria menor ou igual a $5 \mu \mathrm{m}$.

Os experimentos foram realizados com a colocação das partículas de pó, com cerca de $200 \mathrm{mg}$, em cinco cadinhos de aço inoxidável 316L (de $30 \mathrm{~mm}$ de diâmetro por $3 \mathrm{~mm}$ de altura), totalizando aproximadamente $1.000 \mathrm{mg}$.

\subsection{Equipamento de Redução}

Os experimentos de redução foram realizados em reator de plasma pulsado DC modelo Thor NP da marca SDS, pertencente ao laboratório de Redução do Instituto Federal do Espírito Santo (Ifes), campus Vitória.

O reator utilizado nos experimentos é composto por:

- Uma câmara cilíndrica de aço inoxidável austenítico AISI 304, com 500 mm de diâmetro e 750 mm de altura;

- fonte de tensão DC (descarga contínua) máxima de $675 \mathrm{~V}$ e frequência de 3,4 kHz;

- sistema de vácuo capaz de atingir pressões abaixo de 1,0 Pa (0,01 Torr);

- sistema de alimentação de gases, constituído de cilindro de gás hidrogênio e fluxímetros com vazão máxima de $\mathrm{H}_{2}$ de $500 \mathrm{~cm}^{3} / \mathrm{min}$ e válvulas de regulação.

A temperatura da superfície dos cadinhos foi medida com auxílio de termopar e a pressão através de um manômetro Baratron do tipo 120MKS.

\subsection{Procedimento de Aquecimento e Redução}

Para o aquecimento, aplicou-se uma d.d.p entre eletrodos de $540 \mathrm{~V}$, fez-se um vácuo primário $(1,0 \mathrm{~Pa})$ na câmara para remoção do ar e de outros contaminantes do sistema. O gás nitrogênio foi introduzido, e estabilizou-se a pressão em 1 torr. Realizou-se aquecimento até a temperatura de $380^{\circ} \mathrm{C}$ e então o fluxímetro referente ao $\mathrm{N}_{2}$ foi desligado.

Para a redução o $\mathrm{H}_{2}$ e o Ar foram introduzidos na câmara até a pressão de trabalho (4 torr). Após o processo de redução, com o tempo estimado (60 min), a fonte de geração do plasma foi interrompida e as amostras foram resfriadas, ainda no interior da câmara sob vácuo, até a temperatura ambiente.

Os fluxos de argônio e hidrogênio variam de acordo com a tabela 1.

Tabela 1. Fluxos de hidrogênio e argônio em cada experimento

\begin{tabular}{ccc}
\hline \multirow{2}{*}{ Experimento } & \multicolumn{2}{c}{ Fluxos de hidrogênio e argônio $\left(\mathrm{cm}^{3} / \mathrm{min}\right)$} \\
& $\mathrm{H}_{2}$ & $\mathrm{Ar}$ \\
\hline 1 & 400 & - \\
2 & 392 & 8 \\
3 & 380 & 20 \\
4 & 360 & 40 \\
\hline
\end{tabular}

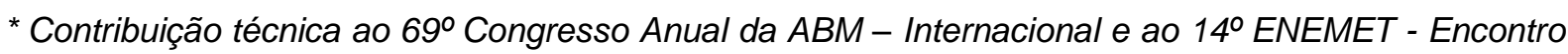
Nacional de Estudantes de Engenharia Metalúrgica, de Materiais e de Minas, 21 a 25 de julho de 2014, São Paulo, SP, Brasil.
} 




\subsection{Gravimetria}

Os cálculos de fração de redução foram realizados através de gravimetria. Para este fim, foi utilizada a balança de alta precisão $(0,0001 \mathrm{~g})$ da marca OHAUS modelo Explorer, pertencente ao do laboratório de Análises Químicas do IFES - campus Vitória.

A fração de redução, $\alpha$, foi determinada de acordo com a Equação 1:

$$
\alpha=\frac{C o+m i-C f}{0,99 \times 0,3 \times m i}
$$

onde, Co é a massa do cadinho, mi é a massa inicial do pó e Cf é a massa final do cadinho mais o pó após a redução.

\subsection{Difração de Raios-x}

Esta técnica de caracterização foi utilizada com o objetivo de realizar a identificação das fases presentes, bem como a evolução do processo de redução em cada experimento que foi realizado. Para este fim, foi utilizado um difratrômetro BRUKER modelo D2 PHASER, pertencente ao Laboratório de Caracterização do Ifes, Campus Vitória.

Os ensaios foram realizados com radiação $\mathrm{Cu} \mathrm{K}-\alpha$, com $2 \theta$ variando de $10^{\circ}$ a $100^{\circ}$, passo de $0,02^{\circ}$ em $2 \theta$, com um tempo de contagem de $1 \mathrm{~s}$ e velocidade de rotação de $60 \mathrm{rpm}$.

\subsection{Microscopia eletrônica de varredura (MEV)}

Observações por microscopia eletrônica de varredura (MEV) foram realizadas a fim de não só caracterizar a morfologia do material reduzido como também complementar os resultados de técnicas anteriores.

As amostras foram fixadas em superfície adesiva condutora e recobertas com paládio por 120 segundos a $40 \mathrm{~mA}$ em um metalizador DENTON VACUUM, modelo DESK V, de modo a torná-las condutoras, adequando-as a análise ao microscópio Eletrônico de Varredura - MEV. O MEV utilizado foi o Zeiss, marca EVO MA10, pertencente ao IFES. As análises foram executadas com $20 \mathrm{kV}$ de tensão de aceleração de elétron, e analisadas no MEV através de imagens formadas pelo detector de elétrons retroespalhados - QBSD e WD - work distance de 8,5 mm.

\section{RESULTADOS E DISCUSSÃO}

\subsection{Gravimetria}

As tabelas 2 a 5 apresentam os resultado de redução respectivos aos experimentos de redução realizados usando diferentes proporções de argônio na atmosfera de redução.

\footnotetext{
* Contribuição técnica ao $69^{\circ}$ Congresso Anual da ABM - Internacional e ao 14ํㅡㄹ ENEMET - Encontro Nacional de Estudantes de Engenharia Metalúrgica, de Materiais e de Minas, 21 a 25 de julho de 2014, São Paulo, SP, Brasil.
} 
$\mathrm{H}_{2}$ fornecem praticamente o mesmo grau de redução que os realizados com $100 \%$ de hidrogênio. Ocorreu uma diminuição significativa no grau de redução quando se usa $10 \%$ de $\operatorname{Ar}$ e $90 \%$ de $\mathrm{H}_{2}$.

Portanto, a redução com o uso de plasma de argônio e hidrogênio só se mostrou eficiente quando é utilizada uma baixa porcentagem de argônio na atmosfera de redução.

\subsection{Difração de Raios - X}

As figuras 4 e 5 mostram os resultados de difração de raios $x$ dos pós antes e após os experimentos de redução.

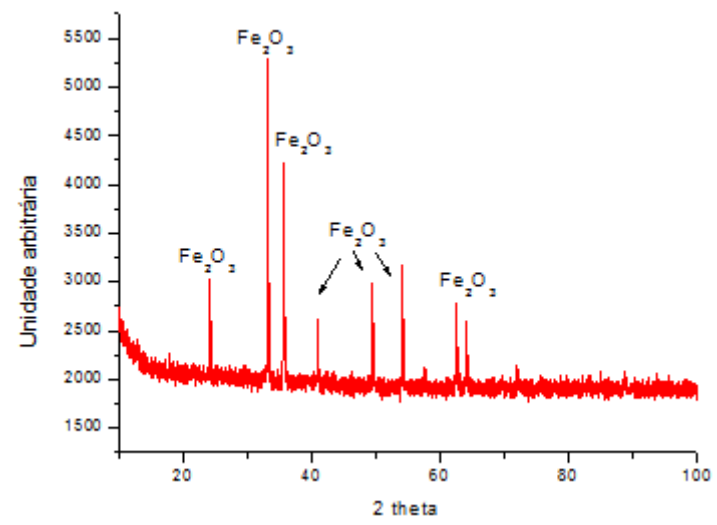

Figura 4. Difratograma de raios $x$ para a hematita antes da redução.
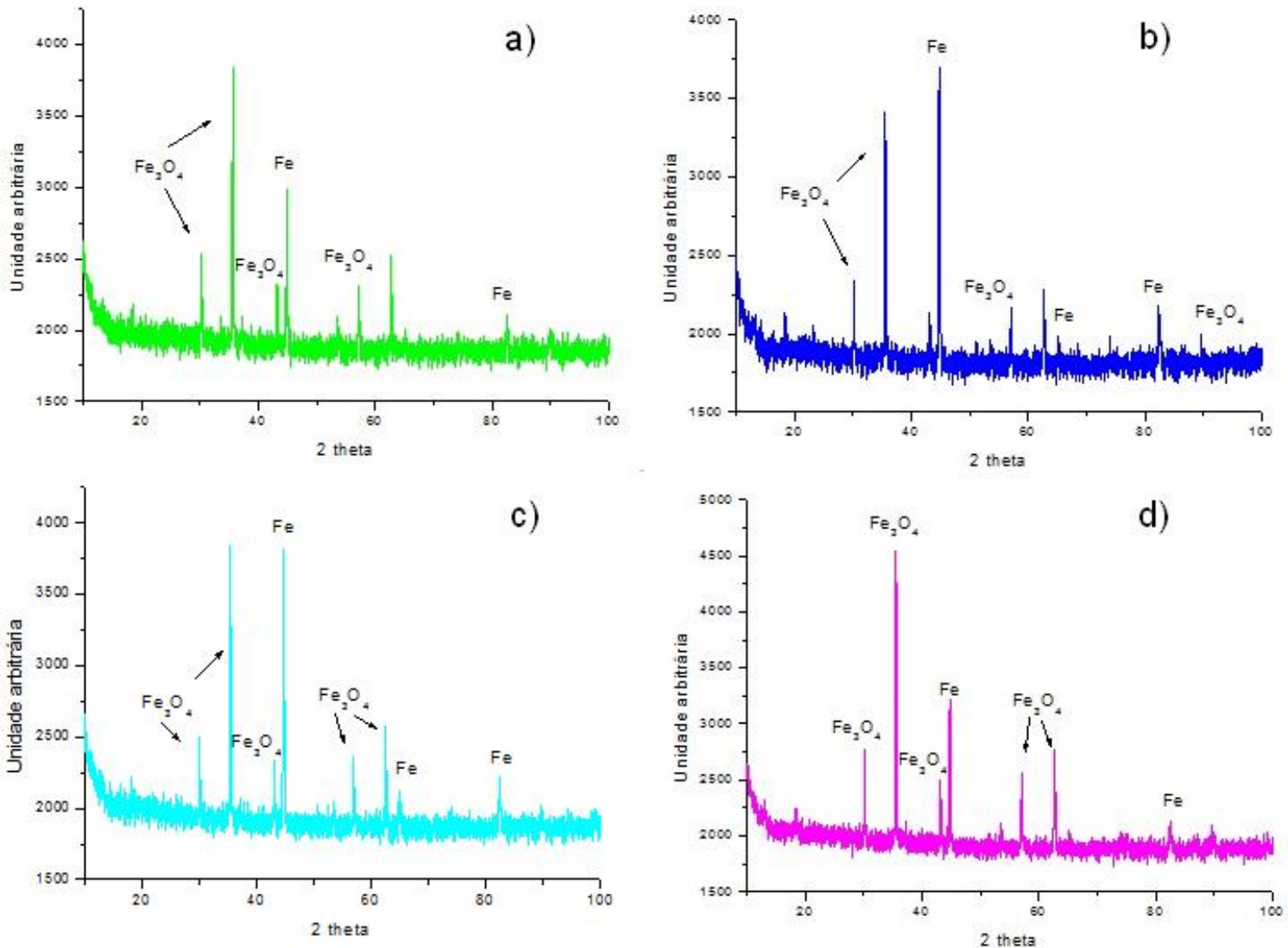

Figura 5. Difratogramas de raios $x$ para as amostras reduzidas: a) $100 \% \mathrm{H}_{2}$; b) $98 \% \mathrm{H}_{2}$ e $2 \% \mathrm{Ar}$; c) $95 \% \mathrm{H}_{2}$ e $5 \%$ Ar; d) $90 \% \mathrm{H}_{2}$ e $10 \%$ Ar.

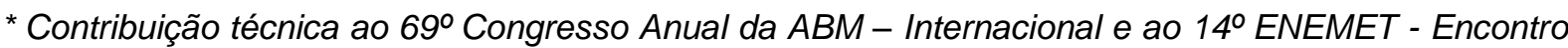
Nacional de Estudantes de Engenharia Metalúrgica, de Materiais e de Minas, 21 a 25 de julho de 2014, São Paulo, SP, Brasil. 
.

Através da difração de raios $\mathrm{x}$ podem ser confirmados os resultados obtidos na gravimetria, uma vez que os picos de ferro metálico ( $\mathrm{Fe}$ ) mais intensos são evidenciados no difratograma correspondente a redução realizada com $98 \% \mathrm{H}_{2}$ e $2 \%$ de $\operatorname{Ar}$ (figura 6 b)). Além disso, observa-se que a hematita foi reduzida em todos os experimentos para magnetita $\left(\mathrm{Fe}_{3} \mathrm{O}_{4}\right)$ ou ferro metálico $(\mathrm{Fe})$.

\subsection{Análise Morfológica (MEV)}

As figuras 6 e 7 mostram as morfologias dos pós antes da redução e após a redução:

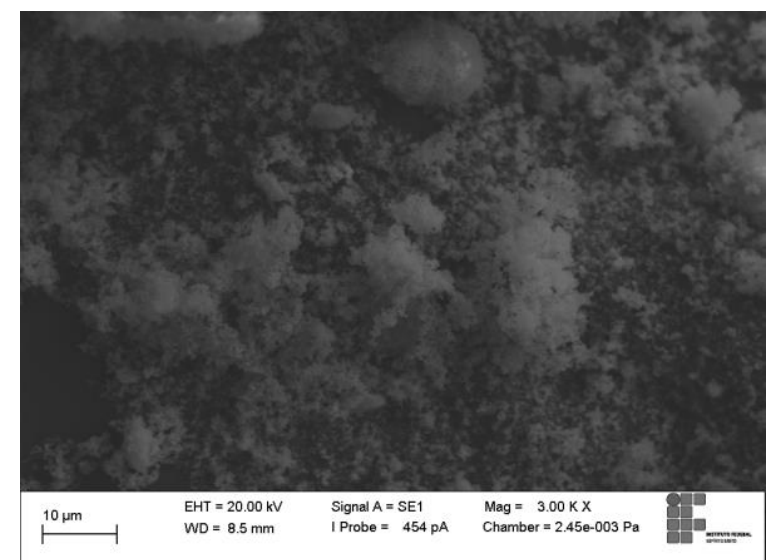

Figura 6. MEV da amostra de hematita antes da redução.

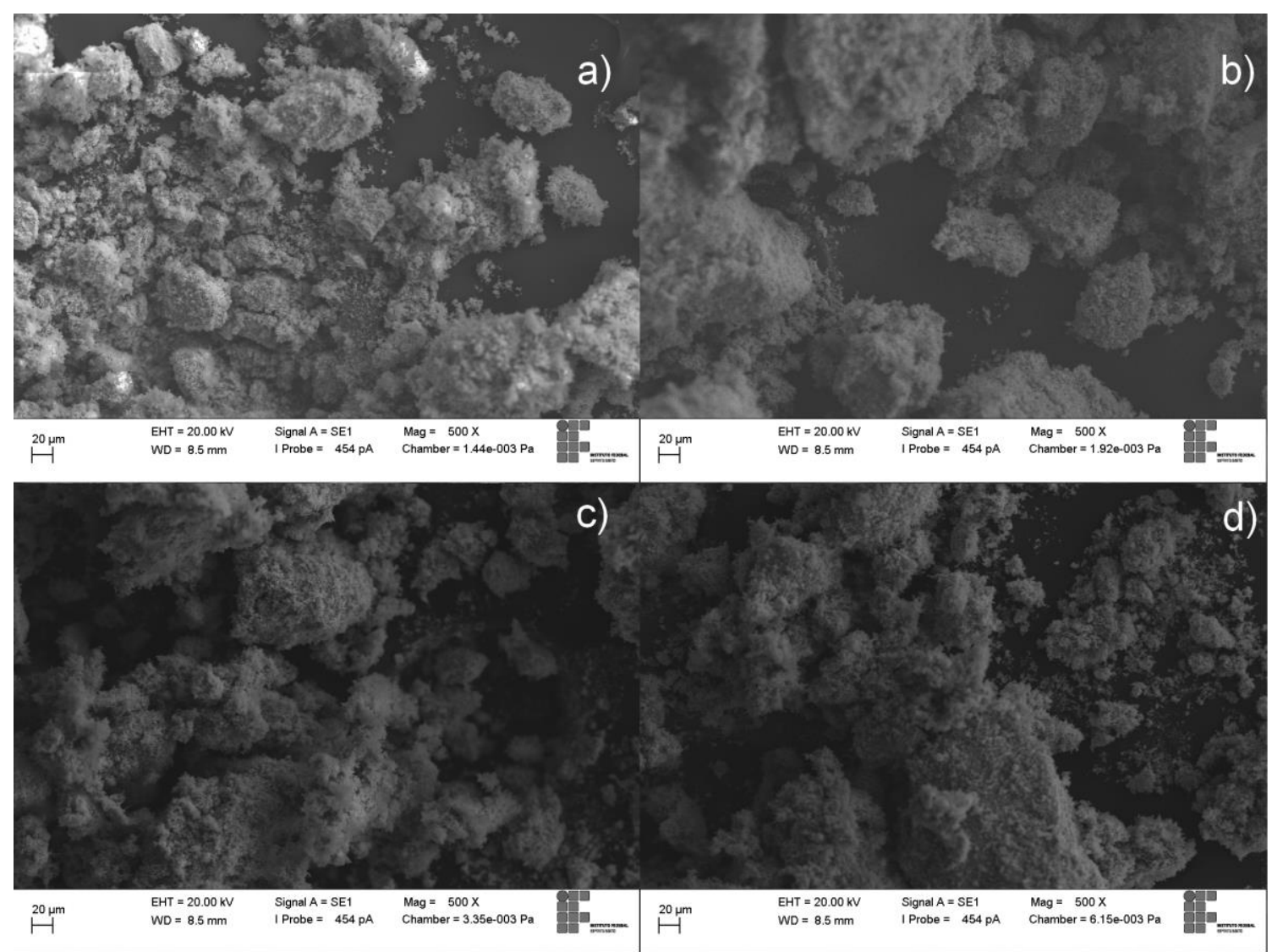

Figura 7. MEV das amostras reduzidas sob plasma de: a) $100 \% \mathrm{H}_{2}$; b) $98 \% \mathrm{H}_{2}$ e $2 \%$ Ar; c) $95 \% \mathrm{H}_{2} \mathrm{e}$ $5 \% \mathrm{Ar}$; d) $90 \% \mathrm{H}_{2}$ e $10 \%$ Ar.

\footnotetext{
* Contribuição técnica ao 69 Congresso Anual da ABM - Internacional e ao 14ํㅡㄹ ENEMET - Encontro Nacional de Estudantes de Engenharia Metalúrgica, de Materiais e de Minas, 21 a 25 de julho de 2014, São Paulo, SP, Brasil.
} 


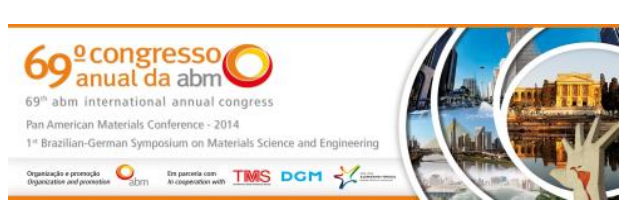

Na figura 6 percebe-se que as partículas estão mais dispersas e menos aderidas. Já na figura 7 não foi possível observar grandes diferenças. Nota-se que as partículas se encontram mais aderidas do que as partículas da figura 6 e possuem um aspecto esponjoso.

\section{CONCLUSÃo}

Para a redução a plasma de pós de hematita, realizada na temperatura de $380^{\circ} \mathrm{C}$, por $60 \mathrm{~min}$, sob pressão de $533 \mathrm{~Pa}$, concluiu-se que o argônio aumenta o grau de redução quando adicionado em baixos teores, como $2 \%$. O uso de concentrações iguais a $5 \%$ de argônio é indiferente, uma vez que se obtém praticamente o mesmo grau de redução quando se faz a redução com $100 \%$ de hidrogênio. A adição de $10 \%$ de argônio se mostrou prejudicial à redução.

\section{Agradecimentos}

O primeiro autor agradece ao Fundo de Apoio a Ciência e Tecnologia, FACITEC, pela bolsa de iniciação científica concedida.

\section{REFERÊNCIAS}

1 Chen GZ, Fray DJ, Farthing TW. Direct electrochemical reduction of titanium dioxide to titanium in molten calcium chloride. Nature, 2000; 407: 361-364, 2000.

2 Norgate TE, Jahanshahi S, Rankin WJ. Assessing the environmental impact of metal production processes. Journal of Cleaner Production, 2007; 15: 838-848.

3 Turkdogan ET, Vinters JV. Gaseous reduction of iron oxides: Part I. Reduction of hematite in hydrogen. Metallurgical Transactions, 1971; 2(11): 3175-3188.

4 Peña MA, Gómez JP, Fierro JLG. New catalytic routes for syngas and hydrogen production. Applied Catalysis A: General, 1996; 144(1-2): 7-57.

5 Zhang Y, Ding W, Guo S, Xu K. Reduction of metal oxide in nonequilibrium hydrogen plasma. The Chinese Journal of Nonferrous Metals, 2004; 14(2): 317-321.

6 Rajput P, Bhoi B, Sahoo S, Paramguru RK, Mishra BK. Preliminary investigation into direct reducion of iron in low temperature hydrogen plasma. Ironmarking and Steelmaking, 2012; 40(1): 61-68.

7 Inan US, Golkowski M. Principles of Plasma Physics for Engineers and Scientists. New York: Cambrige University Press, 2011.

8 Flamm DL. In: Introduction to Plasma Chemistry, Academic Press, Boston, MA, 1989, p. $91-178$.

9 Bullard ED, Lynch CD. Reduction of Titanium Dioxide in a Nonequilibrium Hydrogen Plasma. Metallurgical and Materials Transactions B, 1997; 28(6), p. 1069 - 1080.

10 Bogaerts A, et al. Gas Discharge plasma and their applications. Spectrochimica Acta B, 2002; 57, p. 609-658.

11 Alves Júnior. Nitretação a Plasma: Fundamentos e Aplicações, Natal: Editora UFRN, 2001.

12 Dembovsky V. Zu Fragen der Thermodynamik und Reaktionskinetik in der Plasmametallurgie. Neue Hütte, 1987; 32: 214-219.

\footnotetext{
* Contribuição técnica ao $69^{\circ}$ Congresso Anual da ABM - Internacional e ao 14ํㅡㄹ ENEMET - Encontro Nacional de Estudantes de Engenharia Metalúrgica, de Materiais e de Minas, 21 a 25 de julho de 2014, São Paulo, SP, Brasil.
} 